\title{
Article
}

\section{Sources, topics and use of knowledge by coaches}

Stoszkowski, J., and Collins, D.

Available at http://clok.uclan.ac.uk/12159/

Stoszkowski, J., ORCID: 0000-0002-1968-5770 and Collins, D. ORCID: 00000002-7601-0454 (2016) Sources, topics and use of knowledge by coaches. Journal of Sports Sciences, 34 (9). pp. 794-802. ISSN 0264-0414

It is advisable to refer to the publisher's version if you intend to cite from the work. http://dx.doi.org/10.1080/02640414.2015.1072279

For more information about UCLan's research in this area go to http://www.uclan.ac.uk/researchgroups/ and search for < name of research Group>.

For information about Research generally at UCLan please go to http://www.uclan.ac.uk/research/

All outputs in CLoK are protected by Intellectual Property Rights law, including Copyright law. Copyright, IPR and Moral Rights for the works on this site are retained by the individual authors and/or other copyright owners. Terms and conditions for use of this material are defined in the policies page.

\section{CLoK}

Central Lancashire online Knowledge www.clok.uclan.ac.uk

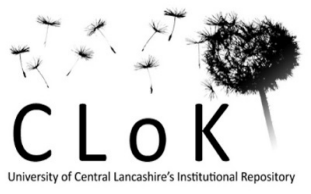




\title{
Sources, topics and use of knowledge by coaches
}

\author{
John Stoszkowski* and Dave Collins
}

Institute of Coaching and Performance, University of Central Lancashire, U.K.

*Corresponding author. School of Sport, Tourism and The Outdoors, The University of Central Lancashire, Preston, PR1 2HE, Tel 01772895702.

Email: JRStoszkowski@uclan.ac.uk; DJCollins@uclan.ac.uk

\section{This is an Accepted Manuscript of an article published by Taylor \& Francis Group in the Journal of Sports Sciences, July 2015, available online: http://dx.doi.org/10.1080/02640414.2015 .1072279}


Sources, topics and use of knowledge by coaches

\begin{abstract}
In recent years, the value of social learning approaches as part of the design and delivery of formalised coach development initiatives has gained credence in the literature. However, insight is currently lacking into the fundamental social dimensions that underpin coach learning. Accordingly, this study aimed to explore coaches' perceptions of their actual and preferred methods of acquiring new coaching knowledge, the types of knowledge they currently acquire and/or desire, and their application of new knowledge. Responses to an online survey, completed by practicing coaches $(N=320)$ in a range of sports and contexts, were analysed descriptively and inductively. Results revealed that coaches' preferred, and mostly acquired, coaching knowledge from informal learning activities, especially when these permitted social interaction. Notably, however, formal coach education courses were also reported relatively frequently as a source of recent knowledge acquisition. Nevertheless, critical justification for and application of, acquired knowledge was largely absent. Based on the findings, we suggest that, before social learning activities such as mentoring schemes and communities of practice are placed at the centre of formalised coach development provision, coach educators must put in place the support structures to better enable coaches to recognise and deal with the potentially mixed influences of the social milieu on coach learning, aiming to ensure that their informal development is sufficiently open-minded, reflective and critical.
\end{abstract}

Keywords: coach learning; coach development; coach education 


\section{Introduction}

An increasing body of research is focused on gaining a better understanding of how coaches develop their craft and learn how to coach (Cushion et al., 2010). Typically, the preferred sources of knowledge acquisition for coaches have been shown to extend far beyond professional "training" courses to a wide and varied range of informal and self-directed learning situations (Cassidy \& Rossi, 2006; Erickson, Bruner, MacDonald, \& Côté, 2008; Lemyre, Trudel, \& Durand-Bush, 2007; Wright, Trudel, \& Culver, 2007). Consequently, in an attempt to recognise this apparent preference for informal development, the value of social learning approaches as part of the design and delivery of formalised coach development initiatives has gained credence in the contemporary sports coaching literature (Cassidy, Potrac, \& McKenzie, 2006; Gilbert, 2009; Mallett, Trudel, Lyle, \& Rynne, 2009). Most commonly, this involves "social constructivist" perceptions of coach learning, whereby an individual is said to construct knowledge as a result of their social experiences and interactions with others (Cushion, 2011). For example, a number of authors have suggested that, through peer interaction and real-world practice, the social construction of coach knowledge can be enhanced though participation in mentoring schemes (Cushion, 2006; Nash, 2003) and various versions of coaches' learning communities (Culver \& Trudel, 2006; Gilbert, Gallimore, \& Trudel, 2009; Trudel \& Gilbert, 2004). Undeniably, social learning approaches provide a great opportunity for coach development; however, insight is still lacking into the fundamental social dimensions that underpin the process of coach learning, and precisely how these concepts can influence coach development for better and for worse (Stoszkowski \& Collins, 2014).

Firstly, there remains a lack of literature looking specifically at what 
motivates coaches to seek and participate in particular educational opportunities, as well as what deters coach learning engagement (Cushion et al., 2010). Similarly, we need to know more about the knowledge sources that coaches view as being more or less important (Irwin, Hanton, \& Kerwin, 2004). For example, if other coaches are indeed (or are going to be) a primary source of knowledge, it is important to determine whether this source is actively selected by coaches, or is only accessed due to convenience or a perceived lack of availability of, or inherent weakness in, other options (Reade, Rodgers, \& Spriggs, 2008). Such information would help coach developers to provide the best learning environment for coaches (Werthner \& Trudel, 2006) and design coach education and development interventions that better fit their perceived needs (Vargas-Tonsing, 2007).

Secondly, our understanding of how informal sources of coaching knowledge interact with other contextual factors involved in the learning process (for good and/or ill) is still in its infancy (Deek, Werthner, Paquette, \& Culver, 2013). Much of a coach's work takes place in a complex, multifaceted and constantly changing social "milieu" (Stoszkowski \& Collins, 2014), which is a powerful driver in promoting and perpetuating the value and acceptance of certain types of knowledge and behaviour over others (Billett \& Somerville, 2004; Cushion, Armour, \& Jones, 2003; Light \& Evans, 2013). In essence, exposure to the subtleties of this milieu (e.g., tradition, historical precedence, workplace hierarchies, cultural practices, social norms) will guide what information coaches pay attention to, as well as influence what they think they need to and, ultimately, choose to learn from their experiences (Cushion, Ford, \& Williams, 2012; Jones, Armour, \& Potrac, 2004; Werthner \& Trudel, 2006). As such, while formal coach certification has been criticised for indoctrinating coaches into a "right" way of coaching (cf. Abraham \& Collins, 
1998), informal learning activities could be equally as powerful in developing and reinforcing particular perspectives on coaching, especially in terms of what is, or is not, considered "good" coaching (Cushion et al., 2010; Grecic \& Collins, 2013). Notably, there has been limited research examining these issues when developing coaching education programmes (Trudel \& Gilbert, 2004); indeed, before we begin strategising ways to utilise and improve informal knowledge acquisition, we need to first understand how it is already taking place (Allee, 2000). For example, we need to know more about the types of knowledge that coaches currently pick up, what they think they need to know more about (i.e., their own perceived development needs), and the knowledge structures that underpin these perceptions and decisions. This information would help us to identify how coaches recognize their strengths and weaknesses, as well as highlight potential topics of relevance and interest for coaches (Vargas-Tonsing, 2007; Wiman, Salmoni, \& Hall, 2010). Similarly, insight into these thought processes would help to identify the degree of congruence between what the coaching research would suggest is the most pertinent knowledge for the development of coaches, and the knowledge that coaches themselves desire and acquire currently (Nelson, Cushion, \& Potrac, 2013).

Finally, coach learning is often at the mercy of socially mediated power relationships and (often deep-seated) values, attitudes, and beliefs, which are often anti-intellectual and conservative in nature (Abraham, Muir, \& Morgan, 2010). As such, in the absence of a sufficiently focussed reflective and critical approach to the consideration of new ideas and the construction of professional knowledge (Hardy \& Mawer, 1999), the potential exists for coaches to simply acquire and reproduce outcome-neutral or even potentially harmful ideological interpretations of knowledge and out-dated or ineffective practices (Cushion et al., 2012; Gilbert \& Trudel, 2001; 
Mallett et al., 2009). Moreover, it has been proposed that coaches may gain greater benefit from informal learning situations if they have a clearer and more structured vision (e.g., a philosophical standpoint) of what type of coach they wish, and perhaps need, to become (Stephenson \& Jowett, 2009). Indeed, Abraham, Collins, and Martindale (2006) suggest that, in the absence of such relevant overarching knowledge structures, coaches are akin to "magpies not filing cabinets," whereby they will often uncritically pick up and mimic "shiny nuggets" from what they perceive as the successful practice of others (Grecic \& Collins, 2013). Consequently, gaining insight into the ways coaches deploy and/or use the information that they are exposed to, and the knowledge that they acquire, is vital in order to determine the extent to which existing practice is simply reproduced at the expense of innovation and/or critical analysis (Reade et al., 2008).

Accordingly, the purpose of the present study was to answer the following research questions, which served as guides in the data analysis:

- What are coaches' self-reported actual and preferred methods of acquiring new coaching knowledge, and why?

- What knowledge do coaches perceive that they currently pick up, and what do they feel they need to know more about in order to be a better coach?

- How do coaches perceive that they deploy/use the new coaching knowledge that they acquire?

\section{Method}

\section{Participants}

Table 1 gives demographic details of the participants $(N=320)$ included in the present study. The sample came from some 26 different countries with 30 different sports represented, and participants reported a range of different levels of 
experience, participation contexts, and qualification. Nevertheless, western countries and sports were most prevalent, with highly qualified, UK based football coaches particularly well represented (see Table 1).

\section{Instrument}

An initial survey, specifically designed for the purposes of the present study, contained nine items derived from a deductive analysis of the eminent coach learning literature (cf. Cushion et al., 2010), and further informed by the two authors; one a university lecturer in sports coaching, and the other a highly experienced consultant in coach development for both developmental and elite level sport. The survey was reviewed for face and content validity (Dillman, 2000) by a panel of experts consisting of an experienced university lecturer with a $\mathrm{PhD}$ in sports coaching, a national governing body (NGB) coach development manager, and a researcher in coaching and physical education. This process resulted in four modifications, with three items removed and one new item included. Next, the revised survey was evaluated for clarity and comprehensibility though a pilot study with a small convenience sample of coaches $(N=12)$ from several sports. The survey took between 7 and 16 minutes to complete, and follow up cognitive interviews (Willis, DeMatio, \& Harris-Kojetin, 1999) resulted in the rewording of four items in order to improve intelligibility and clarity. Following these stages, the final version of the survey was comprised of two sections and 18 items. Section one comprised of seven open-ended questions designed to elicit qualitative responses about the sources the participants consult for coaching knowledge, the types of coaching knowledge they seek and acquire, and the ways they use and apply the knowledge they acquire. The second section contained 11 items designed to elicit demographic information 
including gender, age, location, coaching experience, and level of academic and coaching qualification. A copy of the final instrument is shown as Appendix A.

\section{Procedure}

Prior to data collection, the study received ethical approval from a university research ethics committee. Using opportunity sampling (Brady, 2006), the survey was initially distributed by email to the two authors' existing networks of coaches and gatekeepers of sport (i.e., individuals with access to coaches e.g., NGB staff, club staff, coach educators). The email contained an explanation of the study aims and the voluntary nature of taking part, information about confidentiality and anonymity, and a web link to the survey, which was hosted by the online survey tool SurveyMonkey (www.surveymonkey.com). In an attempt to utilise snowball sampling (Morgan, 2008), the email also encouraged participants to circulate the web link to their own personal networks and coaching peers. In addition, the lead author circulated the web link via his online social networks (e.g., Twitter, LinkedIn), where it was shared and "retweeted" around 120 times. The first page of the survey repeated the information contained in the email, and explained that all answers would remain anonymous. Participants were notified that they should only "click" continue if they were actively coaching a sport, and that by doing so they would give consent for any submitted answers to be used as data in the study. It was also made clear that, because answers were anonymous, they could not be withdrawn once submitted as no names or identifying information were tracked or recorded at any stage of the data collection process, recruitment to which took place over a 10 -week period, and after which the web link became inactive.

\section{Data Analysis}


Following closure of the survey, responses to each item were transferred to separate Microsoft Excel 2010 spreadsheets for further analysis. The open-ended responses to items one to seven, which consisted of a mixture of short statements of less than five words (e.g., "Psychology"; "Tactical knowledge"; "Talking to another coach") and longer, more structured, sentences (e.g., "Two heads they say are better than one. Not necessarily true but through discussion, you pick up new ideas"), were subjected to an inductive content analysis (Patton, 2002) using the data analysis software Nvivo 10 and following a three-stage process (Chesterfield, Potrac, \& Jones, 2010; Côté, Salmela, Baria, \& Russell, 1993; Nelson et al., 2013). During this process, the answers to questions were treated as standalone meaning units, unless they contained more than one self-definable point (e.g., "Discussion with peers and reading books or articles"), in which case they were separated accordingly. Answers that did not contain sufficient information to provide a piece of meaning (less than $1 \%$ of answers) were excluded from the analysis. The meaning units for each item were listed and labelled, before being compared for similarities and organized into raw data themes. The analysis then proceeded to a higher level of abstraction, whereby the raw data themes were built up into larger and more general themes and categories in a higher order concept (Côté et al., 1993). This process allowed for the constant refinement of the results until theoretical saturation occurred (Strauss \& Corbin, 1998) and enabled the quantification of response frequency (Vergeer \& Lyle, 2007).

In order to enhance the validity and trustworthiness of the data, both authors independently familiarized themselves with all of the data by reading through the lists of meaning units at least twice. Then, during a collaborative coding process, they discussed the meaning units, categories and themes at each stage until a 
consensus of opinion was reached on their accuracy and clarity. This discourse resulted in a high level of agreement between authors, with only a small number of minor discrepancies (less that $10 \%$ of data codes) requiring adjustment or further rationale (Sparkes, 1998). Subsequently, and following the recommendations of Krane, Andersen, and Strean (1997), samples of these data sets were re-examined by an independent researcher, blind to the research aims, to audit the assigned categories and themes to ensure they accurately reflected the standalone meaning units. No issues of contention arose. Finally, descriptive demographic data were calculated, providing frequencies and percentages.

\section{Results and Discussion}

The findings of the study are arranged in such an order as to provide answers to each of the original research questions. Percentages shown in the text refer to the percentage of the total number of meaning units generated for each item.

\section{What are coaches' self-reported actual and preferred methods of acquiring new coaching knowledge, and why?}

Consistent with the findings of others studies on the learning sources of coaching knowledge (e.g., Erickson et al., 2008; Lemyre et al., 2007; Mallett et al., 2009), results highlighted that coaches reported primarily gaining recent ideas and information from a variety of informal, self directed learning situations, with other coaches and colleagues being the predominant source (38.66\%, see Table 2$)$.

Moreover, participants were very clear about the extent to which they preferred to acquire knowledge through informal, self-directed learning activities, especially as a result of social interaction with other coaches during their day-to-day coaching experiences (55.36\%, see Table 3). This corroborates findings in previous studies (e.g., Culver \& Trudel, 2006; Irwin et al., 2004; Jones et al., 2004), and is consistent 
with other accounts of peer guidance being a valued source of learning in the workplace (Coetzer, 2007). Interestingly however, and in contrast to the large body of literature that highlights the limited impact of formal modes of learning on the development of coaching knowledge (Abraham et al., 2006; Jones, Armour, \& Potrac, 2003; Lemyre et al., 2007), formal coach education courses were also reported relatively frequently as a source of the recent knowledge that coaches had acquired (24.65\%, see Table 2). This highlights an apparent contradiction revealed by our data. Namely, that the vast majority of coaches suggested that they don't particularly like, or ascribe much importance to, formal learning (only $1.56 \%$ reported positive perceptions, see Table 3); yet, a sizeable proportion of them clearly still used it and had recently learned something from it. Notably, inspection of both these sub-groups suggested no pattern or discriminating factor across age, qualification or experience.

This finding brings into question whether the suggestion that coaches don't "like" formal learning is much less a comment about its effectiveness, and more about its quality/style and/or the way coaches are offered it. For example, when reporting reasons for their learning preferences, coaches clearly valued the opportunity for social interaction $(27.58 \%$, see Table 4$)$, reinforcing the view that they attach great importance to being able to participate in activities such as communities of practice (Cassidy \& Rossi, 2006). This is perhaps unsurprising, especially if we consider the references to convenience and ease of access $(13.45 \%$, see Table 4) in the present study (both common criticisms of formal qualifications, cf. Cushion et al., 2010). After all, coaches can get information relatively quickly and efficiently from the other coaches they interact with (Reade et al., 2008). Furthermore, such guidance is likely to be more clearly applied ("If I were you I 
would do this..." i.e., procedural) rather than more global ("you might like to consider..." i.e., declarative). Similarly, participants clearly attached more value to modes of learning that they viewed as being immediate to the realities of their own coaching practice $(18.72 \%$, see Table 4$)$, another common criticism of formal courses (e.g., Lemyre et al., 2007; Vargas-Tonsing, 2007; Wright et al., 2007). This presents the question; do we simply need to make formal learning more palatable and "real-world" impactful, perhaps by drawing more effectively on social interaction and individual applied experiences during coach education courses (Cassidy et al., 2006; Cushion et al., 2003)? Alternatively, could it be that these opinions are simply the dominant social milieu opinion of formal courses manifest in coaches' perceptions, as opposed to genuine comment on its perceived usefulness? The picture provided by these data leaves these two ideas as tenable hypotheses deserving of greater examination.

\section{What knowledge do coaches perceive that they currently pick up, and what do they feel they need to know more about in order to be a better coach?}

Positively, results indicated that the last thing participants felt they had learned or found useful spanned across the "ologies," sport-specific content knowledge, and pedagogical knowledge (see Table 5), which have all been highlighted as being necessary for coaching excellence (Abraham \& Collins, 1998; Côté \& Gilbert, 2009; Nash \& Collins, 2006). Moreover, the topics that participants felt they needed to know more about broadly reflected this mix of topics (see Table 6), suggesting an element of coherence between the last things that coaches perceived they had learned, what they thought they needed to learn, and what the coaching literature suggests is most pertinent for them to learn. Interestingly, pedagogy was by far the most reported area of recent knowledge acquisition 
(66.04\%, see Table 5), with "specific coaching methods and techniques" in particular being the most commonly reported topic of recent knowledge acquisition $(31.46 \%$, see Table 5 - further support for our contention that coaches prefer procedural information). This perceived need chimes well with other studies that have highlighted this domain as the most significant gap in coaches' knowledge sets (Abraham \& Collins, 2011). As such, it seems that this sample of coaches know what is good for them!

If we consider how this knowledge was most likely to have been acquired, however, some potential contrasts begin to emerge. For example, although the coaches in the present study seemed to assume that knowledge can be passed between coaches in the coaching environment unhindered, the primary purpose of this environment is not coach learning (Cushion et al., 2010); in fact, it may even be resistant to these processes (Abraham et al., 2010; Trudel \& Gilbert, 2004). As such, how do coaches know that the information other coaches share, or the ideas they acquire through observation, is appropriate, or relevant, for their needs? Indeed, what the social milieu encourages coaches to pay attention to, and perceive as relevant for their needs, may not necessarily be in the "right" direction (Light \& Evans, 2013; Nelson et al., 2013). For example, much of the coaching practice that coaches observe and discuss in the coaching environment may well, in and of itself, have been influenced more by tradition, emulation and historical precedence in the sport (Cushion et al., 2003) than through critical consideration of the latest research (Stoszkowski \& Collins, in press). Therefore, just because a "successful" coach uses a specific method or technique, or coaches in a particular way, does not necessarily mean that it will be either appropriate or effective for another coach in another context (Abraham \& Collins, 2011; Cushion et al., 2012); nor will it necessarily 
represent the most up to date, state of the art practice. Likewise, it is not unrealistic to suggest that coaches are at least as likely to observe bad coaching methods, behaviours and techniques, as they are good (Cushion et al., 2003). This means that, although coaches in the present study viewed socially interactive learning episodes with high regard, there is likely to be, at the very least, a degree of variability in terms of what was learnt and how it was subsequently applied (Rynne \& Mallett, 2014; Stephenson \& Jowett, 2009). In short, we suggest that although the coaches seem accurate in their perceptions of what they need (at least against some of the literature), they may not be seeking this in a sufficiently critical fashion or through the best routes. We infer a need to promote the dissemination of declarative (why this and not that) as well as procedural (do this) information as a part of the educational process. Once again, further investigation is merited.

Furthermore, the extent to which it is possible to "learn" about many of the topics identified as necessary by coaches in the present study (e.g., skill acquisition, psychology, athlete development) through informal learning episodes alone is questionable. For example, if coaches are to have meaningful discussions about a topic or subject with their peers, there is a primary knowledge base and/or set of theoretical constructs that the coaches involved need "up front" to enable this to happen effectively (Nash \& Collins, 2006; Stoszkowski \& Collins, in press). For example, although coaches might possess (or at least perceive they possess) procedural (doing) knowledge in relation to their coaching practice (Abraham \& Collins, 1998), lacking the underpinning declarative knowledge (i.e., "why?" knowledge) necessary for understanding this content can limit critical discussion of the topic (such as skill acquisition) in sufficient depth so as to facilitate optimal learning. This is especially so if the coaches involved in the interaction already 
possess strong but incorrect procedural knowledge in the domain or topic. Consider, for example, the extent to which coaches in the present study reported a clear and coherent awareness of why they needed a particular piece of information or knowledge (see Table 7). Although many answers pertained to the fact that this new knowledge would "make sessions more effective" (20.70\%, see Table 7), or "help meet needs of participants" (16.89\%, see Table 7$)$, very little justification was actually offered for why this would be the case and how the knowledge would help the coach. Indeed, previous research has highlighted that coaches often make decisions without any reference to an established coaching process model, and, instead rely largely on "feelings" and intuition (Cushion et al., 2010; Nash \& Collins, 2006). Similarly, Yates and Tschirhart (2006) suggest that people are often reluctant to use formalistic knowledge (e.g., established formal "known" rules, procedures or theories) when making judgements, and instead prefer to use substantive knowledge (e.g., personal theories or "folk" rules) when possible. These inconsistencies involve significant implications for coach development which merit more detailed investigation.

How do coaches perceive that they deploy/use the new coaching knowledge that they acquire?

The apparent disconnect between the topics coaches reported they wanted information on, and the lack of structure to the reasoning for why they wanted those topics, suggests that many may have lacked an overarching knowledge structure, or schematic, against which they compared and contrasted new knowledge or information (Abraham et al., 2006). Indeed, the majority of coaches in the present study reported that they had immediately and uncritically utilised their most recently acquired knowledge to inform their own coaching practice $(73.07 \%$, see Table 8$)$. 
While Schön (1983) endorses the need for experimentation as a characteristic of professional practice, there is surely an equal need for this experimentation to take place against a significant knowledge structure, which enables the critical evaluation of both process and outcome against informed expectation or quasi hypotheses. Indeed, the lack of such structures (declarative knowledge against which both the veracity and appropriateness of procedures may be evaluated) has already been highlighted in other support professions (Cesna \& Mosier, 2005; Martindale \& Collins, 2013). Similarly, internal learning situations, that is, specific moments when coaches reflect on and reorganize what they already know (Werthner \& Trudel, 2006), were very rarely mentioned as a source of $(1.96 \%$, see Table 2$)$, or preference for $(1.79 \%$, see Table 3$)$, learning. Only in the second factor was some discriminatory pattern apparent, with the eight coaches concerned weighted towards more experienced and more highly qualified participants.

This suggests that participants may lack a reflective orientation to their practice (Stoszkowski \& Collins, 2014), despite a number of researchers (e.g., Gilbert \& Trudel, 2001; Irwin et al., 2004) highlighting that critical reflection, whereby coaches' question and challenge current practice, habits, routines, values and beliefs against clear and justifiable criteria (such as the knowledge structures to which we refer earlier) is vitally important in the development of mental models (Cushion et al., 2012) and advanced practice (Yates \& Tschirhart, 2006). In the absence of such a conscious evaluative process and critical approach to new ideas, there is clear potential for the coaches in the present study to simply become inculcated with the dominant culture (Jarvis, 2009; Stephenson \& Jowett, 2009), especially if their main source of learning was other coaches in the coaching environment. Similarly, the use of the other self directed learning activities reported 
in the present study (e.g., the Internet, books etc., see Table 2) must surely be approached with the application of appropriate filters and/or evaluative processes in order to prevent conservative repetition and reproduction of potentially undesirable practices and information simply being accepted at face value (Jones et al., 2004; Rynne \& Mallett, 2014). Indeed, it may be the development of this knowledge base a priori may serve to enhance the impact and validity of learning from informal experiences (cf. Stoszkowski \& Collins, in press).

\section{Conclusions}

Offering some corroboration to the findings of previous research, the results of the present study highlight that coaches' prefer, and reportedly mostly acquire coaching knowledge from, informal, self-directed learning sources, especially when they permit social interaction. Crucially, however, although the knowledge that coaches sought and picked up from these sources was broadly in line with what contemporary research would prescribe, self-reported evidence for critical justification for, and application of, this knowledge was largely absent. Whilst we accept the survey approach utilised in the current study made it difficult to ask direct questions relating to explicit evidence, we feel justified in suggesting that coaches are approaching new information in a less than optimum fashion; specifically, by being insufficiently critical and overly specific. For example, the last thing coaches had learned was commonly used immediately and in an explicit situation, as opposed to as a general rule (i.e., procedurally rather than declaratively), and empirical/academic research evidence for this practical application was lacking.

Based on these findings, we suggest that before social learning activities such as mentoring and learning communities are placed at the centre of formalised provision (e.g., Culver, Trudel, \& Werthner, 2009; Gilbert et al., 2009; Nash, 2003), 
coach educators could beneficially enable coaches to better recognise and deal with the potentially mixed and unregulated influences of the social milieu on learning (Nelson, Cushion, \& Potrac, 2006). For example, the topics that coaches appear to want knowledge on, and the lack of reasoning as to why they want those topics, are, we feel, suggestive of the necessity for some element of "up front" formal learning, in order to equip coaches with the structures to ensure their informal development is sufficiently open-minded, reflective and critical (Gilbert et al., 2009; Wiman et al., 2010). A planned coach learning "episode," aimed at uncovering and challenging the (often unconscious) pre-existing values (cf. Stoszkowski \& Collins, in press) and beliefs that coaches may have acquired on a specific topic (Cassidy et al., 2006; Cushion et al., 2012), and linking them with current coach practice and behaviour, could go some way to weakening potentially incorrect or misappropriate coaching knowledge (Abraham \& Collins, 1998). Building on this, context specific theoretical knowledge and evidence could be introduced in a way so as to provoke debate and raise awareness of potentially more appropriate or "effective" constructs in relation to that topic (Werthner \& Trudel, 2006). Over time, in order to check, re-visit, and monitor the appropriateness of new beliefs and knowledge, periodic planned learning episodes could then be interspersed with the on-going interactions taking place in the practical coaching context (cf. De Lyon \& Cushion, 2013). Using such declaratively based critical approaches, formal coach education would move beyond the simple transference of specific knowledge and skills, and instead, help coaches to move toward a more critical understanding of their thinking, reasoning, and behaviour (Abraham et al., 2010; Cushion et al., 2003).

Of course, we acknowledge the inherent weaknesses of the survey approach used in the current study to categorically confirm some of these proposals (e.g., low 
control of the data collection environment, potential biases in the way participants perceive questions, lack of ability to clarify and probe views, cf. Evans \& Mathur, 2005). Nevertheless, the survey design utilised has enabled a larger scale and perhaps more representative overview of coaches' perceptions. Therefore, future research might prospectively explore how formal courses and learning activities can better develop complex skills such as reflection (Deek et al., 2013), while meeting the perceived learning needs and preferences of coaches. Such research would generate examples of the different ways in which coach educators can facilitate this "training," and support coaches in the use of such strategies (Mallett et al, 2009) in such a way that is both efficient and effective. For example, the role of online technology in accessing coaching knowledge is increasingly recognised (Sports Coach UK, 2013), however, the full interactive potential of the Internet for the social construction of coaching knowledge alongside and/or during formal coach development activities is largely unexplored.

\section{References}

Abraham, A., \& Collins, D. (1998). Examining and extending research in coach development. Quest, 50, 59-79.

Abraham, A., \& Collins, D. (2011). Taking the next step: Ways forward for coaching science. Quest, 63, 366-384.

Abraham, A., Collins, D., \& Martindale, R. (2006). The coaching schematic: Validation through expert coach consensus. Journal of Sport Sciences, 24(6), 549-564. 
Abraham, A., Muir, B., \& Morgan, G. (2010). UK centre for coaching excellence scoping project report: national and international best practice in Level 4 coach development. Leeds: Leeds Metropolitan University.

Allee,V. (2000). Knowledge networks and communities of practice. OD Practitioner Online, 32(4).

Billett, S., \& Somerville, M. (2004). Transformations at work: Identity and learning. Studies in Continuing Education, 26(2), 309-326.

Brady, A. (2006). Opportunity Sampling. In V. Jupp (Ed.), The SAGE dictionary of social research methods (pp. 205-206). London: Sage Publications.

Cassidy, T., Potrac, P., \& McKenzie, A. (2006). Evaluating and reflecting upon a coach education initiative: The CoDe of rugby. The Sport Psychologist, 20(2), 145-161.

Cassidy, T., \& Rossi, T. (2006). Situating learning: (Re)examining the notion of apprenticeship in coach education. International Journal of Sports Science and Coaching, 1(3), 235-246.

Cesna, M., \& Mosier, K. (2005). Using a prediction paradigm to compare levels of expertise and decision making among critical care nurses. In H. Montgomery, R. Lipshitz, \& B. Brehmer (Eds.), How professionals make decisions (pp. 107117). London: LEA.

Chesterfield, G., Potrac, P., \& Jones, R. (2010). 'Studentship' and 'impression management' in an advanced soccer coach education award. Sport, Education and Society, 15(3), 299-314.

Coetzer, A. (2007). Employee perceptions of their workplace as learning environments. Journal of Workplace Learning, 19(7), 417-434. 
Côté, J., \& Gilbert, W. (2009). An integrative definition of coaching effectiveness and expertise. International Journal of Sport Science and Coaching, 4, 307323.

Côté, J., Salmela, J. H., Baria, A., \& Russell, S. H. (1993). Organizing and interpreting unstructured qualitative data. The Sport Psychologist, 7(2), 127137.

Culver, D., \& Trudel, P. (2006). Cultivating coaches' communities of practice: Developing the potential for learning through interactions. In R. L. Jones (Ed.), The sports coach as educator: re-conceptualising sports coaching (pp. 97-112). London: Routledge.

Culver, D., Trudel, P., \& Werthner, P. (2009). A sport leader's attempt to foster a coaches' community of practice. International Journal of Sports Science \& Coaching, 4(3), 365-383.

Cushion, C. (2006). Mentoring: Harnessing the power of experience. In R. Jones (Ed.), The sports coach as educator: Re-conceptualising sports coaching (pp. 128-144). London: Routledge.

Cushion, C. (2011). Coaches' learning and development. In I. Stafford (Ed.), Coaching children in sport (pp. 57-69). London: Routledge.

Cushion, C. J., Armour, K. M., \& Jones, R. L. (2003). Coach education and continuing professional development: Experience and learning to coach. Quest, $55,215-230$.

Cushion, C., Ford, P. R., \& Williams, M. (2012). Coach behaviours and practice structures in youth soccer: Implications for talent development. Journal of Sports Sciences, 30(15), 1631-1641. 
Cushion, C., Nelson, L., Armour, K., Lyle, J., Jones, R., Sandford, R., \& O'Callaghan, C. (2010). Coach learning and development: A review of literature. Leeds: Sports Coach UK.

Deek, D., Werthner, P., Paquette, K. J., \& Culver, D. (2013). Impact of a large-scale coach education program from a lifelong-learning perspective. Journal of Coaching Education, 6(1), 23-42.

De Lyon, A. T., \& Cushion, C. J. (2013). The acquisition and development of fitness trainers' professional knowledge. The Journal of Strength and Conditioning Research, 27(5), 1407-1422.

Dillman, D. A. (2000). Mail and Internet surveys: The tailored design method. New York, NY: John Wiley \& Sons Inc.

Erickson, K., Bruner, M. W., Macdonald, D. J., \& Côté, J. (2008). Gaining insight into actual and preferred sources of coaching knowledge. International Journal of Sports Science and Coaching, 3(4), 527-538.

Evans, J. R., \& Mathur, A. (2005). The value of online surveys. Internet Research, 15(2), 195-219.

Gilbert, W. (2009). Formal vs. informal coach education: A commentary. International Journal of Sports Science and Coaching, 4, 335-337.

Gilbert, W. D., \& Trudel, P. (2001). Learning to coach through experience: Reflection in model youth sport coaches. Journal of Teaching in Physical Education, 21, 16-34.

Gilbert, W., Gallimore, R., \& Trudel, P. (2009). A learning community approach to coach development in youth sport. Journal of Coaching Education, 2(2), 1-21.

Grecic, D., \& Collins, D. (2013). The epistemological chain: Practical applications in sports. Quest, 65(2), 151-168. 
Hardy, C. A., \& Mawer, M. (1999). Learning and teaching in physical education. London: Falmer.

Irwin, G., Hanton, S., \& Kerwin, D. (2004). Reflective practice and the origins of elite coaching knowledge. Reflective Practice, 5, 426-442.

Jarvis, P. (2009). Learning to be a person in society. London: Routledge.

Jones, R. L., Armour, K. M., \& Potrac, P. (2003). Constructing expert knowledge: A case study of a top-level professional soccer coach. Sport, Education and Society, 8, 213-229.

Jones, R. L., Armour, K. M., \& Potrac, P. (2004). Sports coaching cultures: From practice to theory. London: Routledge.

Krane, V., Andersen, M. B., \& Strean, W. B. (1997). Issues of qualitative research methods and presentation. Journal of Sport and Exercise Psychology, 19, 213218.

Lemyre, F., Trudel, P., \& Durand-Bush, N. (2007). How youth sport coaches learn to coach. The Sport Psychologist, 21, 191-209.

Light, R. L., \& Evans, J. R. (2013). Dispositions of elite-level Australian rugby coaches towards game sense: Characteristics of their coaching habitus. Sport, Education \& Society, 13(3), 407-423.

Mallett, C. J., Trudel, P., Lyle, J., \& Rynne, S. B. (2009). Formal vs. informal coach education. International Journal of Sports Science \& Coaching, 4, 325-337.

Martindale, A. \& Collins, D. (2013). The development of professional judgment and decision making expertise in applied sport psychology. The Sport Psychologist, $27,390-398$. 
Morgan, D. (2008). Snowball sampling. In L. Given (Ed.), The SAGE encyclopedia of qualitative research methods (pp. 816-817). Thousand Oaks, CA: Sage Publications.

Nash, C. (2003). Development of a mentoring system within coaching practice. Journal of Hospitality, Leisure, Sport \& Tourism Education, 2(2), 39-47.

Nash, C., \& Collins, D. (2006). Tacit knowledge in expert coaching: Science or art? Quest, 58, 465-477.

Nelson, L. J., Cushion, C. J., \& Potrac, P. (2006). Formal, nonformal and informal coach learning: A holistic conceptualization. International Journal of Sports Science and Coaching, 1, 247-259.

Nelson, L., Cushion, C., \& Potrac, P. (2013). Enhancing the provision of coach education: The recommendations of UK coaching practitioners. Physical Education and Sport Pedagogy, 18(2), 204-218.

Patton, M. Q. (2002). Qualitative research and evaluation methods (3rd ed.). Thousand Oaks, CA: Sage Publications.

Reade, I., Rodgers, W., \& Spriggs, K. (2008). New ideas for high performance coaches: A case study of knowledge transfer in sport science. International Journal of Sports Science and Coaching, 3(3), 335-354.

Rynne, S. B., \& Mallett, C. J. (2014). Coaches' learning and sustainability in high performance sport. Reflective Practice, 15(1), 12-26.

Schön, D. (1983). The reflective practitioner: How professionals think in action. New York, NY: Basic Books.

Sparkes, A. C. (1998). Validity in qualitative inquiry and the problem of criteria: Implications for sport psychology. The Sport Psychologist, 12, 363-386. 
Sports Coach UK (2013). The appetite for online coach education: Now and the future. Leeds: Sports Coach UK.

Stephenson, B., \& Jowett, S. (2009). Factors that influence the development of English youth soccer coaches. International Journal of Coaching Science, 3(1), 3-16.

Stoszkowski, J., \& Collins, D. (2014). Communities of practice, social learning and networks: Exploiting the social side of coach development. Sport, Education and Society, 19(6), 773-788.

Stoszkowski, J., \& Collins, D. (in press). What makes them so good? The constructs used by coaches to identify coaching prowess. Athletic Insight.

Strauss, A., \& Corbin, J. (1998). Basics of qualitative research. Thousand Oaks, CA: Sage Publications.

Trudel, P., \& Gilbert, W. (2004). Communities of practice as an approach to foster ice hockey coach development. Safety in Ice Hockey, 4, 167-79.

Vargas-Tonsing, T. M. (2007). Coaches' preferences for continuing coaching education. International Journal of Sports Science and Coaching, 2(1), 25-35.

Vergeer, I., \& Lyle, J. (2007). Mixing methods in assessing coaches' decision making. Research Quarterly for Exercise and Sport, 78, 225-235.

Werthner, P., \& Trudel, P. (2006). A new theoretical perspective for understanding how coaches learn to coach. The Sport Psychologist, 20, 198-212.

Wiman, M., Salmoni, A. W., \& Hall, C. R. (2010). An examination of the definition and development of expert coaching. International Journal of Coaching Science, 4(2), 37-60.

Willis, G. B., DeMatio, T. J., \& Harris-Kojetin, B. (1999). Is the bandwagon headed to the methodological Promised Land? Evaluating the validity of cognitive 
interviews. In M. G. Sirken, D. J. Hermann, S. Schechter, N. Schwarz, J. M. Tanur, \& R. Tourangeau (Eds.), Cognition and research (pp. 133-153). New York, NY: Wiley.

Wright, T., Trudel, P., \& Culver, D. (2007). Learning how to coach: The different learning situations reported by youth ice hockey coaches. Physical Education and Sport Pedagogy, 12(2), 127-144.

Yates, J. F., \& Tschirhart, M. D. (2006). Decision-making expertise. In K. A.

Ericsson, N. Charness, R. R. Hoffman, \& P. J. Foltovich (Eds.), The

Cambridge handbook of expertise and expert performance (pp. 288-311). New York, NY: Cambridge University Press.

Appendix A

Final instrument used in data collection

\section{Section One}

1. State the main thing you feel you need to know more about in order to be a better coach.

2. Why do you feel that is the case?

3. State the last thing you learned which you found useful for your coaching.

4. Where did this idea or information come from?

5. How have you used the idea or information since you got it?

6. What would you say is your most preferred way to gain coaching knowledge?

7. Give 3 reasons why you prefer this method of gaining coaching knowledge

Section Two 
1. Gender

2. What is your age?

3. In which country are you based?

4. Are you a volunteer coach or paid?

5. What is the highest level of coaching qualification you hold?

6. What is your current level of academic education?

7. How long have you been coaching?

8. What sport or sports do you predominantly coach?

9. What level of participant were/are you in this sport?

10. What age groups do you coach?

11. What level of participants do you coach? 
Table 1

Demographic Details of Participants

\begin{tabular}{|c|c|c|c|}
\hline & $\begin{array}{c}\text { Number o } \\
\text { coaches }\end{array}$ & & $\begin{array}{c}\text { Number of } \\
\text { coaches }\end{array}$ \\
\hline \multicolumn{4}{|l|}{ Gender } \\
\hline Male & 289 & Female & 31 \\
\hline \multicolumn{4}{|l|}{ Age range } \\
\hline 18 or less & 1 & $19-29$ & 133 \\
\hline $30-44$ & 129 & $45-60$ & 53 \\
\hline 60 or more & 4 & & \\
\hline \multicolumn{4}{|c|}{ Country where participants are based } \\
\hline $\mathrm{UK}$ & 217 & USA & 28 \\
\hline Ireland & 14 & Australia & 12 \\
\hline Canada & 8 & Germany & 7 \\
\hline India & 4 & Switzerland & 4 \\
\hline South Africa & 3 & Qatar & 2 \\
\hline Austria & 2 & Norway & 2 \\
\hline Poland & 2 & Sweden & 2 \\
\hline United Arab Emirates & 2 & Spain & 1 \\
\hline Finland & 1 & Netherlands & 1 \\
\hline Nepal & 1 & Thailand & 1 \\
\hline New Zealand & 1 & Hungary & 1 \\
\hline Turkey & 1 & Ghana & 1 \\
\hline Chile & 1 & China & 1 \\
\hline \multicolumn{4}{|c|}{ Level as a participant in sport coached } \\
\hline Never a participant & 5 & Novice & 37 \\
\hline Intermediate & 170 & Elite & 107 \\
\hline \multicolumn{4}{|c|}{ Number of years coaching experience } \\
\hline $0-2$ years & 29 & $3-5$ years & 84 \\
\hline $6-9$ years & 72 & 10 years or more & 135 \\
\hline \multicolumn{4}{|l|}{ Age groups coached } \\
\hline Ages 3-6 & 89 & Ages 7-10 & 181 \\
\hline Ages $11-14$ & 217 & Ages $15-18$ & 207 \\
\hline Ages $18-21$ & 160 & Ages 21 and over & 162 \\
\hline \multicolumn{4}{|l|}{ Deployment status } \\
\hline Paid & 227 & Voluntary & 93 \\
\hline \multicolumn{4}{|c|}{ Current level of formal coaching qualification } \\
\hline No qualification & 31 & Foundation & 47 \\
\hline Intermediate & 108 & Advanced & 134 \\
\hline
\end{tabular}


Level of academic qualification

Below higher education

Higher education degree

$51 \quad$ In higher education $\quad 68$

86 Postgraduate 115

Sport coached

Football (soccer)

Rugby (union or league)

Basketball

Athletics/track and field

Netball

Muli-skills

Cycling

Rowing

Baseball/softball

Triathlon

Badminton

Archery

Rounders

Volleyball

Figure skating

\begin{tabular}{clc}
141 & Golf & 54 \\
45 & Cricket & 28 \\
18 & Hockey & 11 \\
11 & Swimming & 9 \\
6 & Tennis & 5 \\
5 & Gaelic AA sports & 4 \\
4 & Ice hockey & 3 \\
3 & Squash & 2 \\
2 & Weightlifting & 2 \\
2 & Australian rules & 2 \\
2 & Gymnastics & 2 \\
2 & Dodgeball & 1 \\
1 & Watersports & 1 \\
1 & Horseriding & 1 \\
1 & American football & 1 \\
\hline
\end{tabular}

Note. Coaches could select all options that applied. 50 participants reported coaching more than one sport. 
Table 2

Participants' Perceived Source of Last Thing They had Learned or Found Useful

\begin{tabular}{|c|c|c|c|c|c|}
\hline Raw Data Theme & No. (\%) & Lower Order Theme & No. (\%) & Umbrella Theme $^{\mathrm{a}}$ & No. $(\%)$ \\
\hline Coaching course & $48(13.45)$ & & & & \\
\hline University/college course & $40(11.2)$ & Formal coach education & $88(24.65)$ & Formal learning & $88(24.65)$ \\
\hline Workshop/clinic & $14(3.92$ & $\sqrt{3}$ & & & \\
\hline Conference & $9(2.52)$ & Attending CPD activities & $22(6.44)$ & Nonformal learning & $23(6.44)$ \\
\hline Another coach & $98(27.45)$ & & & & \\
\hline Watching others & $22(6.16)$ & Other coaches/colleagues & $138(38.66)$ & & \\
\hline Mentor & $10(2.80)$ & & 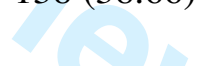 & & \\
\hline Sport scientist & $8(2.24)$ & & & & \\
\hline Online social networks & $16(4.48)$ & & & Informal learning & $246(68.91)$ \\
\hline Internet unspecified & $13(3.65)$ & & & & \\
\hline Specific website & $7(1.96)$ & Internet & $43(12.04)$ & & \\
\hline YouTube & $7(1.96)$ & & & & \\
\hline Coaching experience & $23(6.44)$ & Practical experience & $36(10.08)$ & & \\
\hline
\end{tabular}




\begin{tabular}{lccc} 
Reflection & $7(1.96)$ & \\
Use of coaching aids & $6(1.68)$ & & \\
\hline Books/magazines & $23(6.44)$ & Reading & $29(8.12)$ \\
Academic journals & $6(1.68)$ &
\end{tabular}

Note. Numbers and percentages relate to standalone meaning units generated during data analysis.

${ }^{a}$ See Nelson et al. (2006) for conceptualization of learning types. 
Table 3

Participants' Preferred Methods of Acquiring Coaching Knowledge

\begin{tabular}{|c|c|c|c|c|c|}
\hline Raw Data Theme & No. $(\%)$ & Lower Order Theme & No. $(\%)$ & Umbrella Theme $^{\mathrm{a}}$ & No. $(\%)$ \\
\hline Coaching courses & $7(1.56)$ & Formal coach education & $7(1.56)$ & Formal learning & $7(1.56)$ \\
\hline Seminars/workshops & $21(4.67)$ & 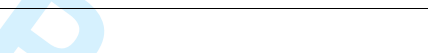 & & & \\
\hline Conferences & $5(1.12)$ & Attending CPD activities & $26(5.80)$ & Nonformal learning & $26(5.80)$ \\
\hline Peer discussion & $186(41.52)$ & 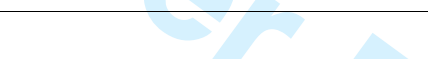 & & & \\
\hline Watching other coaches & $50(11.16)$ & Other coaches/colleagues & $248(55.36)$ & & \\
\hline Mentor coach & $12(2.68)$ & & & & \\
\hline Coaching practice & $22(4.91)$ & & & & \\
\hline Reflection & $8(1.79)$ & Practical experience & $30(6.70)$ & & \\
\hline Websites & $41(9.15)$ & & & lommat Ieall & $(92.05)$ \\
\hline Online social networks & $22(4.91)$ & Internet & $76(16.96)$ & & \\
\hline YouTube & $13(2.90)$ & & & & \\
\hline Books & $53(11.83)$ & & & & \\
\hline Academic journals & $8(1.79)$ & Reading & $61(13.61)$ & & \\
\hline
\end{tabular}


Note. Numbers and percentages relate to standalone meaning units generated during data analysis.

${ }^{\mathrm{a}}$ See Nelson et al. (2006) for conceptualization of learning types. 
Table 4

Participants' Self-Reported Reasons for Preferring Particular Methods of Acquiring

Coaching Knowledge

\begin{tabular}{|c|c|c|c|}
\hline Raw Data Theme & No. $(\%)$ & Higher Order Theme & No. $(\%)$ \\
\hline Facilitates peer interaction & $89(9.98)$ & \multirow{7}{*}{ Social interaction } & \multirow{6}{*}{$246(27.58)$} \\
\hline Can ask questions and seek advice & $48(5.38)$ & & \\
\hline Can learn from others' experience & $39(4.37)$ & & \\
\hline Permits sharing of ideas and best & $31(3.48$ & & \\
\hline Provides access to range of viewpoints & $27(3.03)$ & & \\
\hline Opportunity to network & $12(1.35)$ & & \\
\hline Good for learning & $92(10.31)$ & & \multirow{3}{*}{$215(24.10)$} \\
\hline Relevant and quality information & $77(8.63)$ & \multirow[t]{2}{*}{ Perceived quality } & \\
\hline Interesting and enjoyable & $46(5.16)$ & & \\
\hline Convenience and ease of access & $120(13.45)$ & \multirow{3}{*}{ Logistics } & \multirow{3}{*}{$172(19.28)$} \\
\hline Tailored to my needs & $46(5.16)$ & & \\
\hline Cost & $6(0.67)$ & & \\
\hline Involves hands-on practice & $77(8.63)$ & \multirow{3}{*}{ Grounded in reality } & \multirow{3}{*}{$167(18.72)$} \\
\hline Can see "in action" & $62(6.95)$ & & \\
\hline Realistic & $28(3.14)$ & & \\
\hline Supplies new ideas & $68(7.62)$ & \multirow[b]{2}{*}{ Provides direction } & \multirow[b]{2}{*}{$92(10.31)$} \\
\hline Suggests next steps & $24(2.69)$ & & \\
\hline
\end{tabular}

Note. Numbers and percentages relate to standalone meaning units generated during data analysis. 
Table 5

Last Thing Participants' Perceived They had Learned or Found Useful for Their Coaching

\begin{tabular}{|c|c|c|c|}
\hline Raw Data Theme & No. $(\%)$ & Higher Order Theme & No. $(\%)$ \\
\hline $\begin{array}{l}\text { Specific coaching method or } \\
\text { technique }\end{array}$ & $101(31.46)$ & & \\
\hline Communication & $34(10.59)$ & & \\
\hline Specific new drill & $32(9.97)$ & & \\
\hline Skill acquisition & $16(4.98)$ & Pedagogy & $212(66.04)$ \\
\hline Effective planning & $11(3.43)$ & & \\
\hline Performance analysis & $11(3.43)$ & & \\
\hline Coaching tool or technology & $7(2.18)$ & & \\
\hline $\begin{array}{l}\text { Technical knowledge } \\
\text { Tactical knowledge }\end{array}$ & $\begin{array}{l}29(9.03) \\
16(4.98)\end{array}$ & $\begin{array}{l}\text { Sport specific } \\
\text { knowledge }\end{array}$ & $45(14.02)$ \\
\hline Self awareness & $14(4.36)$ & & \\
\hline Athlete development & $24(7.48)$ & Development & $38(11.84)$ \\
\hline Psychology & $20(6.23)$ & & \\
\hline Physiology & $4(1.25)$ & "Ologies" & $26(8.1)$ \\
\hline Biomechanics & $2(0.62)$ & & \\
\hline
\end{tabular}

Note. Numbers and percentages relate to standalone meaning units generated during data analysis. 
Table 6

Participants' Perceptions of What They Need to Know More About to be a Better Coach

\begin{tabular}{|c|c|c|c|}
\hline Raw Data Theme & No. $(\%)$ & Higher Order Theme & No. $(\%)$ \\
\hline How to coach & $79(23.51)$ & \multirow{5}{*}{ Pedagogy } & \multirow{5}{*}{$154(45.83)$} \\
\hline Skill acquisition & $34(10.12)$ & & \\
\hline Communication & $29(8.63)$ & & \\
\hline "Pedagogy" & $6(1.79)$ & & \\
\hline Performance analysis & $6(1.79)$ & & \\
\hline Psychology & $31(9.23)$ & \multirow{5}{*}{ "Ologies" } & \multirow{5}{*}{$71(21.13)$} \\
\hline Physiology & $19(5.65)$ & & \\
\hline Biomechanics & $11(3.27)$ & & \\
\hline Child development & $8(2.38)$ & & \\
\hline "Sports science" & $2(0.60)$ & & \\
\hline Tactical knowledge & $27(8.04)$ & \multirow{4}{*}{ Sport specific knowledge } & \multirow{4}{*}{$59(17.56)$} \\
\hline Technical knowledge & $18(5.36)$ & & \\
\hline Knowledge of the sport & $10(2.98)$ & & \\
\hline Knowledge of other sports & $4(1.19)$ & & \\
\hline Participant needs & $37(11.01)$ & \multirow{2}{*}{ Development } & \multirow{2}{*}{$52(15.48)$} \\
\hline Self awareness & $15(4.46)$ & & \\
\hline
\end{tabular}

Note. Numbers and percentages relate to standalone meaning units generated during data analysis. 
Table 7

Why Participants Perceive They Need the Knowledge Reported in Table 6

\begin{tabular}{lc}
\hline Raw Data Theme ${ }^{\mathrm{a}}$ & No. (\%) \\
\hline Would make coaching sessions more effective & $76(20.70)$ \\
Would help meet needs of participants & $62(16.89)$ \\
Lack of knowledge/understanding & $61(16.62)$ \\
Perceived requirement & $45(12.26)$ \\
Desire to improve /progress & $33(8.99)$ \\
Would help understand needs of participants & $29(7.90)$ \\
Current area of weakness & $20(5.45)$ \\
Lack of relevant experience & $13(3.54)$ \\
Needed to in order to stay up to date & $13(3.54)$ \\
Would help understand decision making & $10(2.72)$ \\
Would help athlete/team win & $3(0.82)$ \\
Feedback from others & $2(0.54)$ \\
\hline Note. Numbers and &
\end{tabular}

Note. Numbers and percentages relate to standalone meaning units generated during data analysis.

${ }^{\mathrm{a}}$ Raw data themes were somewhat unrelated and did not cluster into an obvious higher order structure. 
Table 8

How Participants' Perceive They Have Used the Knowledge Acquired in Table 5

\begin{tabular}{lccc}
\hline Raw Data Theme & No. (\%) & Higher Order Theme & No. (\%) \\
\hline Applied/used in practice immediately & $175(54.18)$ & Uncritical & \\
Altered coaching behaviour & $43(13.31)$ & application & $236(73.07)$ \\
Used in session planning & $18(5.57)$ & & \\
\hline Base for further thought/reflection & $39(12.07)$ & & \\
Experimented and adapted for own & $22(6.81)$ & Considered further & \\
context & & & \\
\hline Haven't used yet & $26(8.05)$ & Haven't used yet & $26(8.05)$ \\
\hline
\end{tabular}

Note. Numbers and percentages relate to standalone meaning units generated during data analysis. 